\title{
Comparison between Dynamic Hip Screw and Proximal Femoral Nail in Patients with Pertrochanteric Fractures
}

\author{
Muhammad Khurram Habib, ${ }^{1}$ Rana Dawood Ahmad Khan, ${ }^{2}$ Allah Rakha ${ }^{3}$ \\ 1,2,3Department of Orthopedics, Faisalabad Medical University, DHQ Hospital, Faisalabad Pakistan
}

\section{ABSTRACT}

Objective: To compare dynamic hip screw and proximal femoral nail in patients with pertrochanteric fractures in terms of frequency of infection and union. Study Design: It was a randomized controlled trial. Settings: This study was carried at Department of Orthopedic Surgery, DHQ Teaching Hospital Faisalabad-Pakistan. Duration: 1 year from March 2017 to March 2018. Methodology: This study involved 60 patients belonging both genders having age between 20-70 years undergoing pertrochanteric fracture surgery. By random division of these patients, two treatment groups were made; Group- $A(n=30)$ patients underwent fracture fixation with DHS while those in Group-B $(n=30)$ were treated with proximal femoral nailing. Outcome variable was frequency of infection (diagnosed clinically upon appearance of any two of the following signs within 4 weeks after operation; redness around the wound, serosangious discharge and fever $>100^{\circ} \mathrm{F}$ ) and union (clinical and radiological) at 12 weeks follow-up that was noted for making comparison between the two groups. A written informed consent was taken from all the participating patients. Results: The mean age of the patients was $54.80 \pm 8.57$ years. There was a female predominance with male to female ratio of 1:1.4. The frequency of union was significantly higher $(86.7 \%$ vs. $46.7 \% ; p=0.001)$ while the frequency of infection was significantly lower $(0.0 \%$ vs. $30.0 \% ; p<0.001)$ in patients managed with PFN as compared to conventional practice of DHS regardless of patient's age and gender. Conclusion: Proximal femoral nail was found superior to DHS in terms of significantly higher frequency of union and decreased risk of infection in patients with pertrochanteric fractures regardless of patient's age and gender which advocates preferred use of proximal femoral nail in future practice provided the necessary hardware and surgical skills are available.

Keywords: Pertrochanteric Fracture, Union, Infection, Dynamic Hip Screw, Proximal Femoral Nail.

Corresponding Author

Submitted for Publication: 16-12-2019

Dr. Muhammad Khurram Habib, Assistant Professor of Orthopedics, Faisalabad Medical University, DHQ Hospital, Faisalabad Pakistan.

Email: khurramhabibortho@gmail.com

Citation: Habib MK, Khan RDA, Rakha A. Comparison between Dynamic Hip Screw and Proximal Femoral Nail in Patients with Pertrochanteric

Fractures. APMC 2020;14(2):144-8.

DOI: $10.29054 / A P M C / 2020.810$

\section{INTRODUCTION}

Proximal femur metaphyseal fractures involving region between the shaft and the femoral neck are called pertrochanteric fractures. These fractures are also described as intertrochanteric fractures ${ }^{1}$. Pertrochanteric fracture of the proximal femur is the most common fracture of the femur, and its incidence is rising due to increased life expectancy and osteoporosis throughout the Globe. ${ }^{2}$ The lifetime risk of pertrochanteric fractures at 50 years of age is estimated to be $5.6 \%$ for men and $20 \%$ for women. ${ }^{1,2}$ In elder age, pertrochanteric fractures of the proximal femur occurs very commonly. ${ }^{3}$ With the advanced age in populations, it is expected that its incidence will rise even more. ${ }^{2}$ Loss of independence, high rates of morbidity and mortality are associated with these fractures. ${ }^{3,4,5}$ Almost all cases need surgical fixation and at present there are lots of options for fixation of these fractures. ${ }^{3}$ The Dynamic Hip Screw (DHS) is one of such devices that allow controlled dynamic sliding of the lag screw over the barrel of the side plate and allows dynamic compression while weightbearing to stabilize the femur so that it may undergo remodeling and proper fracture healing. Without any association with major complication, sound bone healing is allowed by DHS. ${ }^{6}$ Though in treating fractures of proximal femur, this device is taken as gold standard yet numerous new devices are also available in the market with improved outcomes. ${ }^{3}$ Proximal femoral nail (PFN) is the latest and the best implant for unstable intertrochanteric femoral fractures. Potential advantages of this cephalomedullary device are efficient load transfer and shorter lever arm which results in less transfer of the stress \& less implant failures with added advantage of rotation control. Intramedullary location limits sliding, so less deformity and shortening. Less soft tissue dissection, shorter operative time, and lesser blood loss are also the upsides of PFN.7,8

A number of recent studies comparing DHS with PFN reported that the frequency of radiological union was higher with PFN while the risk of post-operative infection was lower than DHS which favor its preferred use in future orthopedic practice. However, there was controversy among the existing studies (Table 5 \& 6). ${ }^{9-24}$ Present study was necessitated by existing controversy and unavailability of locally published such material.

\section{METHODOLOGY}

Study Design: It was a randomized controlled trial.

Settings: This study was carried at Department of Orthopedic Surgery, DHQ Teaching Hospital Faisalabad-Pakistan.

Duration: 1 year from March 2017 to March 2018.

Sample Size: Sample size of 60 cases (30 in each group) was calculated with $80 \%$ power of test, $95 \%$ significance level while 
taking expected frequency of union to be $83.0 \%$ with PFN and $44.0 \%$ with DHS in patients with pertrochanteric fractures. ${ }^{8}$

Inclusion Criteria: Patients having pertrochanteric fracture belonging to both the genders with ages in the range of the 2070 years were included in this study.

Exclusion Criteria: Patients with pathological fractures, poly trauma patients and those with documented infection were excluded.

Data Collection Procedure: After taking all necessary lab tests besides a fitness certificate from anesthetist, the patients were prepared for surgery. Patients were divided into two random groups. Patients in Group-A underwent fracture fixation with DHS and those in Group-B were fixed with PFN. Patients were explained both the procedures. Informed written consent for study was taken before doing the procedure. Patients were taken care in the immediate postoperative period and were discharged after patients were stable. In OPD their follow up was made and patients were evaluated for infection (diagnosed clinically upon appearance of any two of the following signs within 4 weeks after operation; redness around the wound, serosangious discharge and fever $>100^{\circ} \mathrm{F}$ ) and union both clinically (defined as absence of pain or tenderness and ability to walk without aid at three month post-operatively) and radiologically (defined as solid bridging callus connecting the fracture fragments on both sides on both AP and lateral views at three month post-operatively).

Mean \pm sd has been used to present numerical variables like age. Percentage and frequency have been used to present categorical variables like gender, fracture union and postoperative infection. To compare the frequency of post-operative infection and fracture union between the groups Chi-square test was applied taking $p$-value $\leq 0.05$ as statistically significant. All the procedures were performed by a single surgical team utilizing single operative technique to minimize bias.

\section{RESULTS}

The patients had mean age of $54.80 \pm 8.57$ years. Female to male ratio of patients was $1.4: 1$ as there were $35(58.3 \%)$ female and $25(41.7 \%)$ male patients as given in Table 1.

Table 1: Participant's demographic characteristics

\begin{tabular}{|l|c|}
\hline \multicolumn{1}{|c|}{ Characteristics } & Participants $\mathbf{n = 6 0}$ \\
\hline Age (years) & $54.80 \pm 8.57$ \\
\hline $40-55$ years & $33(55.0 \%)$ \\
\hline $56-70$ years & $27(45.0 \%)$ \\
\hline Gender & \\
\hline Female & $35(58.3 \%)$ \\
\hline Male & $25(41.7 \%)$ \\
\hline
\end{tabular}

difference was statistically insignificant

Comparison of both the study groups was made in terms of mean age $(p=0.929)$ and distribution of various groups based on age $(p=0.795)$ and gender $(p=0.432)$ as given in Table 2 .
Table 2: Demographic characteristics of study groups Independent sample t-test and chi-square test, observed

\begin{tabular}{|c|c|c|c|}
\hline Characteristics & PFN $(n=30)$ & DHS $(n=30)$ & $P$ value \\
\hline Age (years) & $54.90 \pm 8.28$ & $54.70 \pm 8.99$ & 0.755 \\
\hline 40-55 years & $17(56.7 \%)$ & $16(53.3 \%)$ & \multirow{2}{*}{0.795} \\
\hline $56-70$ years & $13(43.3 \%)$ & 14 (46.7\%) & \\
\hline \multicolumn{4}{|l|}{ Gender } \\
\hline Male & $14(46.7 \%)$ & $11(36.7 \%)$ & \multirow{2}{*}{0.432} \\
\hline Female & $16(53.3 \%)$ & $19(63.3 \%)$ & \\
\hline
\end{tabular}

Independent sample t-test and chi-square test, observed difference was statistically insignificant.

$9(15.0 \%)$ patients acquired post-operative infection while 40 $(66.7 \%)$ patients had fracture union at 12 weeks follow-up as give in Table 3. The frequency of union was significantly higher $(86.7 \%$ vs. $46.7 \% ; p=0.001)$ while that of infection was significantly lower $(0.0 \%$ vs. $30.0 \%$; $p<0.001)$ in the PFN group in comparison with DHS group as presented in Table 4. Similar significant difference was observed across age and gender groups.

Table 3: Frequency of Post-Operative Infection and Union in Study Sample at 12 weeks follow-up

\begin{tabular}{|c|c|c|c|}
\hline \multicolumn{2}{|c|}{ Outcome } & Frequency (n) & Percent (\%) \\
\hline \multirow{2}{*}{ Union } & Yes & 40 & 66.7 \\
\cline { 2 - 4 } & No & 20 & 33.3 \\
\hline \multirow{2}{*}{ Infection } & Yes & 9 & 15.0 \\
\cline { 2 - 4 } & No & 51 & 85.0 \\
\hline
\end{tabular}

Table 4: Frequency comparison between Infection and Union between the Groups postoperatively

\begin{tabular}{|c|c|c|c|c|}
\hline \multicolumn{2}{|c|}{ Outcome } & PFN (n=30) & DHS (n=30) & \multirow{2}{*}{ P value } \\
\hline \multirow{2}{*}{ Union } & Yes & $26(86.7 \%)$ & $14(46.7 \%)$ & \multirow{2}{*}{$0.001^{*}$} \\
\cline { 2 - 4 } & No & $4(13.3 \%)$ & $16(53.3 \%)$ & \\
\hline \multirow{2}{*}{ Infection } & Yes & $0(0.0 \%)$ & $9(30.0 \%)$ & \multirow{2}{*}{$\leq 0.001^{*}$} \\
\cline { 2 - 4 } & No & $30(100.0 \%)$ & $21(66.7 \%)$ & \\
\hline
\end{tabular}

Chi-square test, " statistically significant difference was observed

\section{DISCUSSION}

Most commonly faced fractures by the orthopedic surgeons are hip fractures having present annual rate of 250,000 in the US. ${ }^{1,2}$ Over the globe, it is expected that by the year 2025, the rate of hip fractures will be at its peak to the tune of 2.6 million and by the year 2050 it will be 4.5 million due to increased life expectancy. It was shown by Gallagher et al. ${ }^{25}$ that the risk of hip fracture is doubled after every 10 -years of age, above the age of fifty years. Restoration within possibly shortest time, treatment without complications, bringing back the level of independence prior to injury is the goals of treating pertrochanteric fractures. In each \& every case, the responsibility of formulating and executing timely effective 
treatment plan in a comprehensive way is given to the surgeon. The purpose behind this is maximizing clinical results in patients of pertrochanteric patents both throughout their life and at injury time. 1,3,25 Dynamic hip screw has always remained conventional implant for the stabilization of fractures among patients with pertrochanteric hip fractures. However, the advent of PFN has revolutionized pertrochanteric fractures with established benefits of increased stability, decreased operative blood loss and early mobilization. Recent studies claimed fracture union rate to be higher while the risk of infection to be lower with PFN but the available evidences had controversy that necessitated present study (Table $5 \&$ Table 6 ).

Table 5: Review of existing literature on frequency of union

\begin{tabular}{|l|l|c|c|}
\hline \multirow{2}{*}{ Author } & \multirow{2}{*}{ Population } & \multicolumn{2}{|c|}{ Union (\%) } \\
\cline { 3 - 4 } & & PFNA & DHS \\
\hline Kumar et al.[9] & Indian & $100.0 \%$ & $96.00 \%$ \\
\hline Gourishankar et al.[10] & Indian & $100.0 \%$ & $98.00 \%$ \\
\hline Gill et al.[11] & Indian & $100.0 \%$ & $100.0 \%$ \\
\hline Karn et al.[12] & Nepalese & $100.0 \%$ & $100.0 \%$ \\
\hline Mulay et al.[13] & Indian & $100.0 \%$ & $98.00 \%$ \\
\hline Yadav et al.[14] & Indian & $100.0 \%$ & $100.0 \%$ \\
\hline Walia et al.[15] & Indian & $100.0 \%$ & $100.0 \%$ \\
\hline Naikwade et al.[16] & Indian & $99.03 \%$ & $94.24 \%$ \\
\hline Gupta et al.[17] & Indian & $98.75 \%$ & $99.17 \%$ \\
\hline Khateeb et al.[18] & Indian & $98.04 \%$ & $98.04 \%$ \\
\hline Naushad et al.[19] & Indian & $97.10 \%$ & $82.90 \%$ \\
\hline Basavaraj et al.[20] & Indian & $97.06 \%$ & $94.11 \%$ \\
\hline Yeganeh et al.[21] & Iranian & $96.66 \%$ & $85.19 \%$ \\
\hline Pundkar et al.[22] & Indian & $92.00 \%$ & $100.0 \%$ \\
\hline Jonnes et al.[[2] & Indian & $86.70 \%$ & $80.00 \%$ \\
\hline Kregor et al.[8] & American & $83.00 \%$ & $44.00 \%$ \\
\hline Suranigi et al.[24] & Indian & $40.00 \%$ & $32.00 \%$ \\
\hline Present Study & Pakistan & $\mathbf{8 6 . 7 0 \%}$ & $\mathbf{4 6 . 7 0 \%}$ \\
\hline
\end{tabular}

Table 6: Review of existing literature of frequency of infection

\begin{tabular}{|l|l|l|l|}
\hline \multirow{2}{*}{ Author } & \multirow{2}{*}{ Population } & \multicolumn{2}{|l|}{ Infection $\mathbf{n ~ ( \% ) ~}$} \\
\cline { 3 - 4 } & & PFN & DHS \\
\hline Pathania et al.[26] & Indian & $6.66 \%$ & $33.33 \%$ \\
\hline Mulay et al.[13] & Indian & $6.00 \%$ & $14.00 \%$ \\
\hline Harisudhan et al. [27] & Indian & $0.00 \%$ & $13.33 \%$ \\
\hline Walia et al.[16] & Indian & $0.00 \%$ & $11.10 \%$ \\
\hline Sridhar et al.[28] & Indian & $8.33 \%$ & $10.53 \%$ \\
\hline Mittal et al.[29] & Indian & $0.00 \%$ & $6.66 \%$ \\
\hline Mallikarjun et al.[30] & Indian & $0.00 \%$ & $6.66 \%$ \\
\hline Ujjal et al.[31] & Indian & $0.00 \%$ & $6.60 \%$ \\
\hline Naikwade et al.[16] & Indian & $0.97 \%$ & $5.77 \%$ \\
\hline Kumar et al.[9] & Indian & $2.50 \%$ & $4.35 \%$ \\
\hline Ranjeetesh et al.[32] & Indian & $0.00 \%$ & $4.00 \%$ \\
\hline Mayi et al..[33] & Indian & $0.00 \%$ & $3.13 \%$ \\
\hline Sharma et al.[34] & Indian & $1.00 \%$ & $2.00 \%$ \\
\hline Gupta et al.[35] & Indian & $0.00 \%$ & $1.25 \%$ \\
\hline Rohra et al..[36] & Indian & $0.00 \%$ & $1.25 \%$ \\
\hline Sahin et al.[37] & Turkey & $0.00 \%$ & $1.16 \%$ \\
\hline Matre et al.[38] & Norway & $0.40 \%$ & $0.80 \%$ \\
\hline Present Study & Pakistan & $0.0 \%$ & $30.0 \%$ \\
\hline
\end{tabular}

Our results are similar to Pathania et al. ${ }^{26}$ who reported comparable mean age of $58.20 \pm 6.7$ years with male to female ratio of 1:1. Similarly, in comparison with PFN, they also showed significantly higher frequency of infection with $\mathrm{DHS}(33.33 \%$ vs. $6.66 \% ; p<0.05)$ as compared to PFN. Mulay et al. ${ }^{13}$ in 2015 (14\% vs. $6 \%$; $p<0.05)$ and Harisudhan et al. ${ }^{27}$ in $2014(13.3 \%$ vs. $0 \% ; p<0.05)$ also reported likewise difference in infection between PFN and DHS. Walia et al. ${ }^{16}$ (2013) reported similar mean age of $52.1 \pm 6.8$ years with female predominance (m:f, $1: 1.5)$ in Indian population of such patients. They too showed significant difference in the frequency of infection between DHS and PFN ( $11.1 \%$ vs. $0 \% ; p<0.05)$. In a similar study, Mallikarjun et al..$^{30}$ (2014) observed mean age of $58 \pm 5.7$ years with much higher female predominance $(1: 2.3)$ in Indian population. In comparison with PFN, a significantly higher frequency of infection with DHS $(6.66 \%$ vs. $0 \%$; $p<0.05)$ was also noted by them. Sridhar et al. ${ }^{28}$ (2014) also reported similar mean age of $56.21 \pm 8.4$ years with relative male predominance $(52.38 \%$ vs. $47.62 \%)$. They however observed insignificant difference in the frequency of infection between DHS and PFN (10.53\% vs. $8.33 \% ; p>0.05)$.

Our results are also comparable to those of Kregor et al. ${ }^{8}$ who had likewise presented significant difference in the frequency of fracture union between PFN (83.00\% vs. $44.00 \%$ ) and DHS. Jonnes et al. ${ }^{23}$ also reported similar frequency $(86.70 \%)$ of fracture union with PFN. Suranigi et al. ${ }^{24}$ reported much lower frequency of $32.00 \%$ for fracture union with DHS.

In local population, current study is first of its kind and has confirmed the supremacy of PFN over DHS in terms of significantly increased frequency of fracture union and lower frequency of postoperative infection irrespective of patient's gender and age. Hence, the hypothesis established at the start of study is well proved and PFN is definitely better than DHS in terms of post-operative infection and fracture union. It can be thus advocated that in future practice proximal femoral nail should be preferred over DHS in patients with intertrochanteric fractures to increase the likelihood of union. We also observed increased frequency of females among such patients which might be attributable to post-menopausal osteoporosis as majority of these cases were from old age group. In the light of this evidence, it can be suggested that minerals replacement should be given to females visiting orthopedic outdoors to minimize the risk of pertrochanteric fracture in later life.

\section{CONCLUSION}

Proximal femoral nail was found superior to DHS in terms of significantly higher frequency of union and decreased risk of infection in patients with pertrochanteric fractures regardless of patient's age and gender which advocates preferred use of proximal femoral nail in future practice provided the necessary hardware and surgical skills are available.

\section{LIMITATIONS}

Failure to compare the frequency of various complications like hardware failure, peri-prosthetic fractures etc. was biggest limitation of this study. 


\section{SUGGESTIONS / RECOMMENDATIONS}

These are also very important and must be considered prior to routine adoption of PFN in clinical practice. Such a study is highly recommended in future research.

\section{CONFLICT OF INTEREST / DISCLOSURE}

None.

\section{ACKNOWLEDGEMENTS}

Special Thanks to Our Head of Department Associate Professor Dr. Rana Dawood Ahmad Khan who guided me and inspired me to do this research work. Most special thanks to patients who allowed me to induct them in this surgical procedure and research work and participated in this research work.

\section{REFERENCES}

1. Douša $P$, Čech $\mathrm{O}$, Weissinger $\mathrm{M}$, Džupa $\mathrm{V}$. Trochanteric femoral fractures. Acta Chir Orthop Traumatol Cech. 2013;80(1):15-26.

2. Kanis JA, Oden A, McCloskey EV, Johansson H, Wahl DA, Cooper C. A systematic review of hip fracture incidence and probability of fracture worldwide. Osteoporos Int. 2012;23(9):2239-56.

3. Chechik O, Amar E, Khashan M, Pritsch T, Drexler M, Goldstein $Y$, et al. Favorable radiographic outcomes using the expandable proximal femoral nail in the treatment of hip fractures - A randomized controlled trial. J Orthop. 2014;11(2):103-9.

4. Dhanwal DK, Dennison EM, Harvey NC, Cooper C. Epidemiology of hip fracture: Worldwide geographic variation. Indian J Orthop. 2011;45(1):15-22.

5. Wright NC, Saag KG, Curtis JR, Smith WK, Kilgore ML, Morrisey $M A$, et al. Recent trends in hip fracture rates by race/ethnicity among older US adults. J Bone Miner Res. 2012;27(11):2325-32.

6. Dhanwal DK, Cooper C, Dennison EM. Geographic variation in osteoporotic hip fracture incidence: the growing importance of Asian influences in coming decades. J Osteoporos. 2010:757102.

7. Ramnarayan V, Vanchi PK, Kumar MM. Intramedullary or Extramedullary fixation for Intertrochanteric fractures - A comparison study. IOSR J Dent Med Sci. 2015;14(9):15-21.

8. Kregor PJ, Obremskey WT, Kreder HJ, Swiontkowski MF; Evidence-Based Orthopaedic Trauma Working Group. Unstable pertrochanteric femoral fractures. J Orthop Trauma. 2005;19(1):63-6.

9. Kumar V, Singh A, Bharti A, Dalmia D, Ali S. A comparison of intramedullary and extramedullary fixation devices in unstable trochanteric fractures. Int J Biomed Adv Res. 2014;5(7):335-9.

10. Gourishankar D. Comparative study of PFN and DHS in proximal femoral fractures. Int $\mathrm{J}$ Recent Trends Sci Technol. 2014;12(3):531-3.

11. Gill SP, Mittal A, Raj M, Singh P, Kumar S, Kumar D. Dynamic hip screw with locked plate VRS Proximal Femoral Nail for the management of intertrochanteric fracture: A comparative study. Int J Orthop. 2017;3(2):173-80.

12. Kam NK, Jain A, Nepal $P$, Singh MP. A prospective randomized control trial comparing proximal femoral nail and sliding hip screw in the management of trochanteric fracture of the femur. Health Renais. 2011;9(1):7-11.

13. Mulay S, Gouri F, Mahajan U. Treatment of Inter-trochantric Fracture by PFN or DHS. Int J Healthcare Biomed Res. 2015;3(3):209-15.
14. Yadav S, Srivastava DC, Shukla M. Comparative evaluation of dynamic hip screw and proximal femoral nail for fracture of intertrochanteric femur. Int J Res Orthop. 2016;2(4):286-90.

15. Walia JP, Tailor H, Mann HS, Gupta AC, Rehncy JS, Singh S. A comparative study of 30 cases of trochanteric fracture femur treated with dynamic hip screw and proximal femoral nailing. Hip. 2013;1(11):6-10.

16. Naikwade DB, Thipse JD, Naikwade AD. Dynamic hip screw versus proximal femoral nail for treatment of trochanteric hip fractures: an outcome analysis with a minimum 2 years of followup. VIMS Health Sci J. 2015;2(4):139-46.

17. Gupta SKV, Valisetti VS. Comparative study between dynamic hip screw vs proximal femoral nailing in inter-trochanteric fractures of the femur in adults. Int J Orthop. 2015;1(1):7-11.

18. Khateeb MK, Satish DG. Comparative study between dynamic hip screw and plate with proximal femoral nailing in trochanteric fractures of femur. Int J Res Orthop. 2017;3(3):602-6.

19. Naushad Hussain NR, Kamat SG. A comparative study of proximal femoral nail versus dynamic hip screw fixation for unstable and complex intertrochanteric fractures of the femur. J Cont Med Dent. 2017;5(2):46-50.

20. Basavaraj S, Kyavater G. Comparative study between dynamic hip screw vs. proximal femoral nailing in unstable intertrochanteric fractures of the femur in adults. J Evo Med Dent Sci. 2015;4(50):8690-3.

21. Yeganeh A, Taghavi $R$, Moghtadaei M. Comparing the intramedullary nailing method versus dynamic hip screw in treatment of unstable intertrochanteric fractures. Med Arch. 2016;70(1):53-6.

22. Pundkar AG, Modi NS, Baitule RW, Pundkar GN. Evaluation of dynamic hip screw plate v/s proximal femoral nail for unstable inter-trochanteric fracture femur. J Res Med Dent Sci. 2016;4(3):283-7.

23. Jonnes C, Shishir SM, Najimudeen S. Type II intertrochanteric fractures: proximal femoral nailing versus dynamic hip screw. Arch Bone Jt Surg. 2016;4(1):23-8.

24. Suranigi SM, Shetty N, Shah HM. Study comparing the advantages of proximal femoral nail over dynamic hip screw among patients with pertrochantric fractures. J Med Thesis. 2014;2(1):35-8.

25. Gallagher JC, Melton LJ, Riggs BL. Examination of prevalence rates of possible risk factors in a population with a fracture of the proximal femur. Clin Orthop Relat Res. 1980;(153):158-65.

26. Pathania VP, Manish S, Sanjay G, Kaushik SK. Management of intertrochanteric fracture by P.F.N vs. D.H.S: a comparative study. J Evo Med Dent Sci. 2015;4(13):6741-50.

27. Harisudhan SR, Kanthimathi B. Comparative study of the management of inter-trochanteric fractures: proximal femoral nail versus dynamic hip screw. Int J Modn Res Revs. 2014;2(10):45962.

28. Sridhar M, Neelakrishnan R. Study of various modalities of surgical management of unstable intertrochanteric fractures. Int J Sci Res Edu. 2014;2(10):2090-108.

29. Mittal CMA, Rallapalli R, Biju R, Prasad SY. Comparison of dynamic hip screw and plate with proximal femoral nail in trochanteric fractures of femur. IOSR J Dent Med Sci. 2015;14(4):73-82.

30. Mallikarjun GB, Arunkumar NK. A study to compare outcome of proximal femoral nailing and dynamic hip screw fixation for intertrochanteric fractures of femur. Eur J Biomed Pharm Sci. 2014;1(3):256-63. 
31. Ujjal B, Ranadeb B. Comparative study between proximal femoral nailing and dynamic hip screw in intertrochanteric fracture of femur. Open J Orthop. 2013;3(3):291-5.

32. Ranjeetesh K, Singh RN. Comparative prospective study of proximal femoral nail and dynamic hip screw in treatment of intertrochanteric fracture femur. J Clin Orthop Trauma. 2012;3(1):28-36.

33. Mayi SC, Shah S, Jidgekar SR, Kulkarni A. Randomized comparative study to evaluate the role of proximal femoral nail and dynamic hip screw in unstable trochanteric fractures. Int $\mathrm{J}$ Res Orthop. 2016;2(3):75-9.

34. Sharma H, Loomba DS. Comparison of outcome of management of unstable pertrochanteric femoral fractures with dynamic hip screw and proximal femoral nail. Afr J Trauma. 2015;4(1):21-6.

35. Gupta SKV, Valisetti VS. Comparative study between dynamic hip screw vs proximal femoral nailing in inter-trochanteric fractures of the femur in adults. Int J Orthop. 2015;1(1):7-11.

36. Rohra N, Trivedi P, Kedia R. Comparative study between dynamic hip screw vs proximal femoral nailing in intertrochanteric fractures of the femur in adults. Int J Sci Res. 2016;5(4):251-2.

37. Sahin O, Demirors H, Akgun R, Senturk I, Tuncay IC. Dynamic hip screw versus proximal femoral nail for treatment of trochanteric hip fractures: an outcome analyses with a minimum 2 years of follow-up. Eur $\mathrm{J}$ Orthop Surg Traumatol. 2012;22(2):473-80.

38. Matre K, Havelin LI, Gjertsen JE, Vinje T, Espehaug B, Fevang JM. Sliding hip screw versus IM nail in reverse oblique trochanteric and subtrochanteric fractures. A study of 2716 patients in the Norwegian Hip Fracture Register. Injury. 2013;44(6):735-42.

\section{AUTHORSHIP CONTRIBUTION}

$\begin{array}{ll}\text { Muhammad Khurram Habib } & \begin{array}{l}\text { Data collection for analysis besides } \\ \text { searching literature on the topic for } \\ \text { writing up manuscript }\end{array} \\ \text { Rana Dawood Ahmad Khan } & \begin{array}{l}\text { Critical Review } \\ \text { Allah Rakha }\end{array} \\ \text { Literature Review }\end{array}$

